\title{
Author Index to Volume 26 - 1999
}

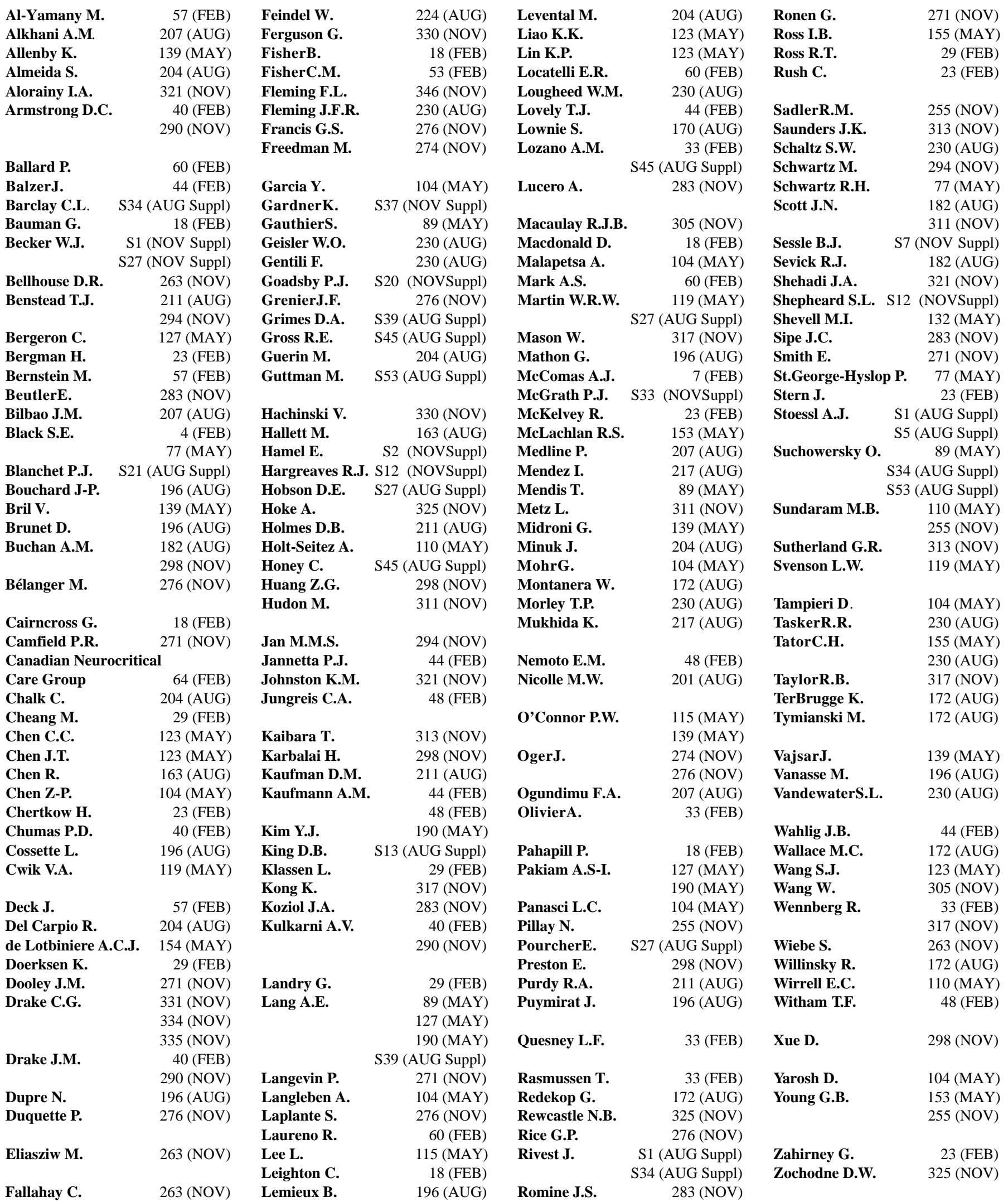




\section{Subject Index to Volume 26 - 1999}

\section{ABSTRACTS}

Abstracts: 34th Meeting of the

Canadian Congress of

Neurological Sciences

Canadian Association of Neuropathologists
Abstracts of papers and cases presented

at the 39th Annual Meeting

$341(\mathrm{NOV})$

\section{ALZHEIMER DISEASE}

Lack of Prognostic Significance of Spect Abnormalities in Non-demented

Elderly Subjects with Memory Loss. 23 (FEB)

Can SPECTPredict the Future for Mild Cognitive Impairment?

4 (FEB)

ApolipoproteinE and Alzheimer's Disease: a Genetic, Molecular \& Neuroimaging Review

AMYOTROPHIC LATERAL SCLEROSIS

The Prevalence of Motor Neurone Disease in the Province of Alberta

ANEURYSMS

Coil Occlusion of Basilar Bifurcation Aneurysms: The Shape of Things to Come 170 (AUG)

Endovascular Occlusion of Basilar Bifurcation Aneurysms With Electrolytically Detachable Coils: Clinical Considerations, Outcome, and Angiographic Results

172 (AUG)

Bleeding Aneurysms of the Basilar Artery:

Direct Surgical Management in

Four Cases

335 (NOV)

ANOXIA

Pseudo-subarachnoid Hemorrhage:

a Rare Neuroimaging Pitfall

$57(\mathrm{FEB})$

ANTIEPILEPTIC DRUGS

Topiramate in Intractable Childhood Onset Epilepsy - A Cautionary Note 271 (NOV)

ASTROCYTOMAS

Low Grade Glioma: A Measuring Radiographic Response to Radiotherapy 18 (FEB)

Relationship Between O6 methylguanineDNAMethyltransferase Levels and Clinical Response Induced by Chloroethylnitrosourea Therapy in Glioma Patients 104 (MAY)

MR Characteristics of Malignant Spinal Cord Astrocytomas in Children

290 (NOV)

AUDIOLOGY

Intraoperative Loss of Auditory Function Relieved By Microvascular Decompression of the Cochlear Nerve

AUTHORSHIP

Message From The Editor

1 (FEB)

AUTONOMIC NERVOUS SYSTEM

Botulism: Heart Rate Variation, Sympathetic Skin Responses, and Plasma Norepinephrine

123 (MAY)

Diffuse Lewy Body Disease Presenting as Multiple System Atrophy

127 (MAY)

BLOOD-BRAIN BARRIER

Biphasic Opening of the Blood-Brain Barrier Following Transient Focal Ischemia: Effects of Hypothermia $298(\mathrm{NOV})$

BOTULINUM TOXIN

Botulism: Heart Rate Variation, Sympathetic Skin Responses, and Plasma Norepinephrine

123 (MAY)

BRAIN DEATH

Guidelines for the Diagnosis of

\section{Brain Death}

Letter to the Editor:

Re: Guidelines for Brain Death) 346 (NOV)

BRAIN TUMOURS

Ganglioglioneurocytoma of the Posterior Fossa

207 (AUG)

Mevalonate Prevents Lovastatin-Induced Apoptosis in Medulloblastoma Cell Lines $\quad 305$ (NOV)

Utility of a Moveable 1.5 Tesla Intraoperative MR Imaging System: Case Report 313 (NOV)

Temporal Dermoid Cyst with a Partial Dermal

Sinus Tract: Case Report

321 (NOV)

\section{CATECHOLAMINES}

Botulism: Heart Rate Variation, Sympathetic Skin Responses, and Plasma Norepinephrine123 (MAY)

\section{CEREBRAL EDEMA}

Biphasic Opening of the Blood-Brain Barrier Following Transient Focal Ischemia: Effects of Hypothermia

298 (NOV)

CEREBROSPINAL FLUID

Access to Multiple Sclerosis Diagnosis for Canadian Neurologists

115 (MAY)

CEREBROVASCULAR DISEASE

Near-Infrared Spectroscopy Monitored Cerebral Venous Thrombolysis 48 (FEB)

Pseudo-subarachnoid Hemorrhage a Rare Neuroimaging Pitfall

Neuroimaging Highlight: Cerebral Autosomal Dominant Arteriopathy with Subcortical Infarcts and Leukoencephalopathy (CADASIL)

$311(\mathrm{NOV})$

\section{CHEMOTHERAPY}

Relationship Between O6 methylguanineDNAMethyltransferase Levels and Clinical Response Induced by Chloroethylnitrosourea Therapy in Glioma Patients 104 (MAY)

CLINICAL TRIALS

Responsiveness of the Scripps Neurologic Rating Scale During a Multiple Sclerosis Clinical Trial

283 (NOV)

COCHLEAR NERVE

Intraoperative Loss of Auditory Function Relieved By Microvascular Decompression of the Cochlear Nerve 44 (FEB) COMA

Guidelines for the Diagnosis of Brain Death

64 (FEB)

COMPUTED TOMOGRAPHY

Pseudo-subarachnoid Hemorrhage: a Rare Neuroimaging Pitfall

Correlation of Neurologic Dysfunction with CT Findings in Early Acute Stroke

82 (AUG)

\section{DEMENTIA}

Lack of Prognostic Significance of SPECT Abnormalities in Non-demented Elderly Subjects with Memory Loss

Can SPECTPredict the Future for Mild Cognitive Impairment?

Diffuse Lewy Body Disease Presenting as Multiple System Atrophy

127 (MAY)

\section{DEPRESSION}

Can SPECTPredict the Future for Mild Cognitive Impairment?

4 (FEB)

DIFFUSE LEWY

Diffuse Lewy Body Disease Presenting as Multiple System Atrophy
EDITORIAL

Editorial Neurosciences in Germany 75 (MAY)

Message From The Editor 1 (FEB)

Can SPECTPredict the Future for Mild Cognitive Impairment?

ApolipoproteinE and Alzheimer's Disease: a Genetic, Molecular and

Neuroimaging Review

77 (MAY)

EDUCATION

Using Problem-Based Learning Approach in Neurosciences Education for Medical Students

EEG - COMPUTER APPLICATIONS

Minimal Standards for Digital/Quantitative Electroencephalography in Canada 153 (MAY) EEG in Epilepsy: Current Perspectives 255 (NOV)

ELECTROCORTICOGRAM

Role of Electrocorticography at Surgery for Lesion-related Frontal Lobe Epilepsy

\section{ELECTROENCEPHALOGRAPHY}

Role of Electrocorticography at Surgery for Lesion-related Frontal Lobe Epilepsy

Guidelines for the Diagnosis of Brain Death 64 (FEB)

Seizures in the Elderly: Etiology and Prognosis

Minimal Standards for Digital/Quantitative Electroencephalography in Canada

Letter to the Editor:

Re: Guidelines for Brain Death

153 (MAY)

ELECTROMYOGRAPHY

EMG Related Anxiety and Pain: A Prospective Study

$346(\mathrm{NOV})$

ELECTROPHYSIOLOGY

The Time Course of Changes in Motor Cortex Excitability Associated with Voluntary Movement

163 (AUG)

ENCEPHALITIS

Reversible Paraneoplastic Encephalomyelitis Associated with a Benign Ovarian Teratoma

317 (NOV)

EPIDEMIOLOGY

Herpes Zoster and Multiple Sclerosis

The Prevalence of Motor Neurone Disease in the Province of Alberta

EPILEPSY

Role of Electrocorticography at Surgery for Lesion-related Frontal Lobe Epilepsy

Seizures in the Elderly: Etiology and Prognosis EG In Epilepsy: Current Perspectives. Burden of Epilepsy:

The Ontario Health Survey
Topiramate in Intractable Childhood Onset Epilepsy - A Cautionary Note 271 (NOV)

ETHICS

Neurosciences in the Third Reich: from Ivory Tower to Death Camps 132 (MAY)

EVENTRELATED POTENTIALS

The World of Touch - From Evoked Potentials to Conscious Perception

7 (FEB)

\section{EVOKED POTENTIALS}

Intraoperative Loss of Auditory Function Relieved By Microvascular Decompression of the Cochlear Nerve 44

The World of Touch - From Evoked Potentials to Conscious Perception

7 (FEB) 
Access to Multiple Sclerosis Diagnosis for Canadian Neurologists 115 (MAY)

GENETICS

ApolipoproteinE and Alzheimer's Disease: a Genetic, Molecular and

Neuroimaging Review

The Genetic Basis of Migraine: How Much Do We Know?

77 (MAY)

\section{HEADACHE}

The Scientific Basis of Migraine Management

Pathophysiology of Migraine New Insights

S37 (NOVSuppl)

The Biology of Serotonin Receptors:

Focus on Migraine Pathophysiology and Treatment

S2 (NOVSuppl)

The Scientific Basis of Medication Choice in Symptomatic Migraine S20 (NOVSuppl)

Evidence Based Migraine Prophylactic Drug Therapy

S27 (NOVSuppl)

Clinical Psychology Issues in

Migraine Headaches

The Genetic Basis of Migraine How Much Do We Know?

Neural Mechanisms and Pathways in Craniofacial Pain

S33 (NOVSuppl)

S37 (NOVSuppl)

S7 (NOVSuppl)

HERNIATION

The Reliability of the "Absent Cistern Sign" in Assessing LPShunt Function

\section{HERPES ZOSTER}

Herpes Zoster and Multiple Sclerosis 29 (FEB)

HISTORY

Neurosciences in the Third Reich: from Ivory Tower to Death Camps

132 (MAY)

The Contributions of W. D. Stevenson to the Development of Neurosurgery in Atlantic Canada

217 (AUG)

E. Harry Botterell: A Series of Papers Commemorating his Life and Contributions

230 (AUG)

Dr. Charles G. Drake 1920 - 1998

Perspectives from Dr. Charles Drake: Early Training in Toronto

$330(\mathrm{NOV})$

$331(\mathrm{NOV})$

Bleeding Aneurysms of the Basilar Artery: Direct Surgical Management in Four Cases 335 (NOV)

\section{HYDROCEPHALUS}

The Reliability of the "Absent Cistern Sign" in Assessing LPShunt Function 40 (FEB)

HYSTERIA

Historical and Clinical Features of Psychogenic Tremor: A Review of 70 Cases 190 (MAY)

\section{IMMUNOLOGY}

Herpes Zoster and Multiple Sclerosis

IGIVin Neurology - Evidence and Recommendations

139 (MAY)

INFARCTION

Correlation of Neurologic Dysfunction with CT Findings in Early Acute Stroke 182 (AUG)

INTENSIVE CARE

Acute Quadriplegic Myopathy Unrelated to Steroids or Paralyzing Agents: Quantitative EMG Studies

INTRAVENOUS IMMUNOGLOBULIN

IGIVin Neurology - Evidence and Recommendations

139 (MAY)

ISCHEMIC BRAIN INJURY

Biphasic Opening of the Blood-Brain Barrier Following Transient Focal Ischemia: Effects of Hypothermia $298(\mathrm{NOV})$
MRI in Vitamin B12 Deficiency Myelopathy 60 (FEB)

Access to Multiple Sclerosis Diagnosis for Canadian Neurologists

115 (MAY)

ApolipoproteinE and Alzheimer's Disease: a Genetic, Molecular and Neuroimaging Review

\section{MAGNETIC STIMULATION}

The Time Course of Changes in Motor Cortex Excitability Associated with Voluntary Movement

163 (AUG)

MCNAUGHTON PRIZE PAPER

Relationship Between O6 methylguanineDNAMethyltransferase Levels and Clinical Response Induced by Chloroethylnitrosourea Therapy in Glioma Patients 104 (MAY)

MEDULLOBLASTOMA

Mevalonate Prevents Lovastatin-Induced: Apoptosis in Medulloblastoma Cell Lines 305 (NOV)

\section{MEMORIAM}

Herbert Henri Jasper (1906-1999): An Appreciation

224 (AUG)

Dr. Charles G. Drake 1920 - 1998 330 (NOV)

Perspectives from Dr. Charles Drake: Early Training in Toronto

$331(\mathrm{NOV})$

MEMORY

Lack of Prognostic Significance of SPECT Abnormalities in Non-demented Elderly Subjects with Memory Loss 23 (FEB)

MIGRAINE

The Scientific Basis of Migraine Management

S1 (NOVSuppl)

Pathophysiology of Migraine New Insights

S12 (NOVSuppl)

The Biology of Serotonin Receptors: Focus on Migraine Pathophysiology and Treatmen S2 (NOVSuppl)

The Scientific Basis of Medication Choice in Symptomatic Migraine S20 (NOVSuppl)

Evidence Based Migraine Prophylactic Drug Therapy

S27 (NOVSuppl)

Clinical Psychology Issues in Migraine Headaches

The Genetic Basis of Migraine: How Much Do We Know? S37 (NOVSuppl)

\section{MOTOR CONTROL}

The Time Course of Changes in Motor Cortex Excitability Associated with Voluntary Movement

163 (AUG)

MOTOR NEURON DISEASE

The Prevalence of Motor Neurone Disease in the Province of Alberta

119 (MAY)

MOVEMENTDISORDERS

Management of Parkinson's Disease: A Review of Current and New Therapies 89 (MAY)

Historical and Clinical Features of Psychogenic Tremor: A Review of 70 Cases 190 (MAY)

Differential Diagnosis of Parkinsonism S1 (AUG Suppl) Parkinson's Disease Levodopa Complications S13 (AUG Suppl)

Rationale for Use of Dopamine Agonists in Parkinson's Disease: Review of Ergot Derivatives

S21 (AUG Suppl)

Ropinirole and Pramipexole, the New Agonists

COMTInhibitors in Parkinson's Disease

S27 (AUG Suppl)

Treatment of Early Parkinson's Disease

S34 (AUG Suppl)

New Developments in the Surgery for S39 (AUG Suppl)

MAGNETIC RESONANCE IMAGING
Parkinson's Disease S45 (AUG Suppl) Etiology of Parkinson's Disease $\quad$ S5 (AUG Suppl)
Parkinson's Disease Management:

Towards a New Paradigm

S53 (AUG Suppl)

MULTIPLE SCLEROSIS

Herpes Zoster and Multiple Sclerosis

29 (FEB)

Access to Multiple Sclerosis Diagnosis for Canadian Neurologists

115 (MAY)

IGIVin Neurology Evidence and Recommendations 139 (MAY)

Consensus Statement of the Canadian MS Clinics Network on: The Use of Disease Modifying Agents in Multiple Sclerosis 274

Treatment with Interferon Beta-1b Improves Quality of Life in Multiple Sclerosis 276 (NOV) Responsiveness of the Scripps Neurologic Rating Scale During a Multiple Sclerosis Clinical Trial $283(\mathrm{NOV})$

MULTIPLE SYSTEM ATROPHY

Diffuse Lewy Body Disease Presenting as Multiple System Atrophy

127 (MAY)

MYASTHENIAGRAVIS

IGIVin Neurology Evidence and Recommendations

139 (MAY)

MYELOPATHY

MRI in Vitamin B12 Deficiency Myelopathy 60 (FEB) MYOPATHY

Acute Quadriplegic Myopathy Unrelated to Steroids or Paralyzing Agents: Quantitative EMG Studies 325 (NOV)

NEURO-ONCOLOGY

Low Grade Glioma: A Measuring Radiographic Response to Radiotherapy

18 (FEB)

Relationship Between O6 methylguanineDNAMethyltransferase Levels and Clinical Response Induced by Chloroethylnitrosourea Therapy in Glioma Patients

104 (MAY)

Ganglioglioneurocytoma of the Posterior Fossa 207 (AUG)

Reversible Paraneoplastic Encephalomyelitis Associated with a Benign

Ovarian Teratoma

$317(\mathrm{NOV})$

NEUROLOGY - GERIATRIC

Seizures in the Elderly: Etiology and Prognosis

110 (MAY)

NEUROMUSCULAR

Pseudo-Myasthenia Gravis and Thymic Hyperplasia in Graves'Disease

Acute Quadriplegic Myopathy Unrelated to

Steroids or Paralyzing Agents:

Quantitative EMG Studies

$325(\mathrm{NOV})$

NEUROPATHOLOGY

Canadian Association of Neuropathologists Abstracts of papers and cases presented at the 39th Annual Meeting

$341(\mathrm{NOV})$

\section{NEUROPATHY}

Clinical and Electrophysiological Study in FrenchCanadian Population with Charcot-Marie-Tooth Disease Type 1AAssociated with 17p11.2 Duplication 196 (AUG) Isolated Trigeminal Neuropathy Due to Trigeminal Nerve Root Hemorrhage 204 (AUG)

NEUROPHYSIOLOGY

The World of Touch - From Evoked Potentials to Conscious Perception

Herbert Henri Jasper (1906-1999): An Appreciation

NEURORADIOLOGY

Low Grade Glioma: A Measuring Radiographic Response to Radiotherapy

The Reliability of the "Absent Cistern Sign" in Assessing LPShunt Function 
Pseudo-subarachnoid Hemorrhage: a Rare Neuroimaging Pitfall

57 (FEB)

Guidelines for the Diagnosis of Brain Death 64 (FEB)

Coil Occlusion of Basilar Bifurcation Aneurysms:

The Shape of Things to Come 170 (AUG)

Endovascular Occlusion of Basilar Bifurcation Aneurysms With Electrolytically Detachable Coils: Clinical Considerations, Outcome, and Angiographic Results $172(\mathrm{AUG})$

MR Characteristics of Malignant Spinal Cord Astrocytomas in Children 290 (NOV)

Neuroimaging Highlight: Cerebral Autosomal Dominant Arteriopathy with Subcortical Infarcts and Leukoencephalopathy (CADASIL) 311 (NOV) Utility of a Moveable 1.5 Tesla Intraoperative MR Imaging System: Case Report 313 (NOV)

NEUROSURGERY

Role of Electrocorticography at Surgery for Lesion-related Frontal Lobe Epilepsy 33 (FEB)

Intraoperative Loss of Auditory Function Relieved By Microvascular

Decompression of the Cochlear Nerve 44 (FEB)

Letter to the Editor

154 (MAY)

Reply to Dr. Lotbiniere's Letter to the Editor

155 (MAY)

Utility of a Moveable 1.5 Tesla Intraoperative MR Imaging System: Case Report 313 (NOV)

Temporal Dermoid Cyst with a Partial Dermal Sinus Tract: Case Report 321 (NOV)

Dr. Charles G. Drake 1920 - $1998 \quad 330$ (NOV)

Perspectives from Dr. Charles Drake: Early Training in Toronto

331 (NOV)

NEUROSURGICAL PRACTICE

The Contributions of W. D. Stevenson to the Development of Neurosurgery in Atlantic Canada

217 (AUG)

E. Harry Botterell: A Series of Papers Commemorating his Life and Contributions

230 (AUG)

\section{NEUROTRANSMITTER}

Botulism: Heart Rate Variation, Sympathetic Skin Responses, and Plasma Norepinephrine123 (MAY)

PAIN

Neural Mechanisms and Pathways

in Craniofacial Pain

S7 (NOVSuppl)

PARKINSON'S DISEASE

Management of Parkinson's Disease: A Review of Current and New Therapies 89 (MAY)

Differential Diagnosis of Parkinsonism S1 (AUG Suppl)

Parkinson's Disease -

Levodopa Complications S13 (AUG Suppl)

Rationale for Use of Dopamine Agonists in

Parkinson's Disease: Review of

Ergot Derivatives

S21 (AUG Suppl)

Ropinirole and Pramipexole, the New Agonists

S27 (AUG Suppl)

COMTInhibitors in Parkinson's Disease

S34 (AUG Suppl)

Treatment of Early Parkinson's Disease

S39 (AUG Suppl)

New Developments in the Surgery for Parkinson's Disease

S45 (AUG Suppl)

Etiology of Parkinson's Disease S5 (AUG Suppl) Parkinson's Disease Management: Towards a New Paradigm S53 (AUG Suppl)

PARKINSONISM

Diffuse Lewy Body Disease Presenting as Multiple System Atrophy

127 (MAY)

\section{PERIPHERAL NERVE}

Phantom Erection after Amputation of Penis: Case Description and Review of the Relevant Literature on Phantoms
Clinical and Electrophysiological Study in FrenchCanadian Population with Charcot-Marie-Tooth Disease Type 1AAssociated with $17 \mathrm{p} 11.2$ Duplication

196 (AUG)

PERIPHERAL NEUROPATHY

IGIVin Neurology -

Evidence and Recommendations 139 (MAY)

\section{PHANTOM LIMB}

Phantom Erection after Amputation of Penis: Case Description and Review of the Relevant Literature on Phantoms

\section{PHARMACOLOGY}

Management of Parkinson's Disease: A Review of Current and New Therapies 89 (MAY)

POLYNEUROPATHY

Clinical and Electrophysiological Study in FrenchCanadian Population with Charcot-Marie-Tooth Disease Type 1AAssociated with 17p11.2 Duplication

196 (AUG)

PSYCHOLOGY

Clinical Psychology Issues in Migraine Headaches

S33 (NOVSuppl)

\section{RADIATION ONCOLOGY}

Low Grade Glioma: A Measuring Radiographic Response to Radiotherapy

18 (FEB)

Letter to the Editor

154 (MAY)

Reply to Dr. Lotbiniere's Letter to the Editor

155 (MAY)

\section{RADIOSURGERY}

Letter to the Editor

Reply to Dr. Lotbiniere's Letter to the Editor

154 (MAY)

\section{SEIZURES}

EEG In Epilepsy: Current Perspectives. 255 (NOV)

Burden of Epilepsy: The Ontario Health Survey 263 (NOV)

Topiramate in Intractable Childhood Onset Epilepsy A Cautionary Note

271 (NOV)

\section{SOMATOSENSORY CORTEX}

Phantom Erection after Amputation of Penis: Case Description and Review of the Relevant Literature on Phantoms

The World of Touch - From Evoked Potentials to Conscious Perception

7 (FEB)

SPECT

Lack of Prognostic Significance of SPECT Abnormalities in Non-demented Elderly Subjects with Memory Loss

Can SPECTPredict the Future for Mild Cognitive Impairment?

ApolipoproteinE and Alzheimer's Disease: a Genetic, Molecular and

Neuroimaging Review

SPINAL CORD

MR Characteristics of Malignant Spinal Cord Astrocytomas in Children

290 (NOV)

\section{STROKE}

Correlation of Neurologic Dysfunction with CT Findings in Early Acute Stroke 182 (AUG)

Biphasic Opening of the Blood-Brain Barrie Following Transient Focal Ischemia: Effects of Hypothermia 298 (NOV)

SUBACUTE COMBINED DEGENERATION

MRI in Vitamin B12 Deficiency Myelopathy 60 (FEB)

\section{SUBARACHNOID HEMORRHAGE}

Pseudo-subarachnoid Hemorrhage: a Rare Neuroimaging Pitfall

Endovascular Occlusion of Basilar Bifurcation Aneurysms With Electrolytically Detachable
Coils: Clinical Considerations, Outcome,

and Angiographic Results

$172(\mathrm{AUG})$

SUPPLEMENTPOLICY

Message From The Editor

1 (FEB)

THERAPEUTICS

Management of Parkinson's Disease: A Review of Current and New Therapies

89 (MAY)

Parkinson's Disease -

Levodopa Complications S13 (AUG Suppl)

Rationale for Use of Dopamine Agonists in

Parkinson's Disease: Review of

Ergot Derivatives

S21 (AUG Suppl)

Ropinirole and Pramipexole, the New Agonists

S27 (AUG Suppl)

COMTInhibitors in Parkinson's Disease

Treatment of Early Parkinson's Disease

Parkinson's Disease Management: Towards a New Paradigm S53 (AUG Suppl)

Topiramate in Intractable Childhood Onset Epilepsy A Cautionary Note 271 (NOV)

Consensus Statement of the Canadian MS Clinics Network on: The Use of Disease Modifying Agents in Multiple Sclerosis

Treatment with Interferon Beta-1b Improves Quality of Life in Multiple Sclerosis 276 (NOV)

The Scientific Basis of Migraine Management S1 (NOVSuppl)

The Biology of Serotonin Receptors: Focus on Migraine Pathophysiology and Treatment

S2 (NOVSuppl)

The Scientific Basis of Medication Choice in Symptomatic Migraine S20 (NOVSuppl)

Evidence Based Migraine Prophylactic Drug Therapy

S27 (NOVSuppl)

THERAPY

Management of Parkinson's Disease: A Review of Current and New Therapies

89 (MAY)

THIRD REICH, GERMANY

Neurosciences in the Third Reich: from Ivory Tower to Death Camps

132 (MAY)

THROMBOLYSIS

Isolated Trigeminal Neuropathy Due to Trigeminal Nerve Root Hemorrhage 204 (AUG)

THYROTOXICOSIS

Pseudo-Myasthenia Gravis and Thymic Hyperplasia in Graves'Disease

201 (AUG)

TRAUMA

Phantom Erection after Amputation of Penis: Case Description and Review of the Relevant Literature on Phantoms 53 (FEB)

UNDERGRADUATE MEDICAL EDUCATION

Using Problem-Based Learning Approach in

Neurosciences Education for

Medical Students

VENOUS THROMBOSIS SPECTROSCOPY

Near-Infrared Spectroscopy Monitored

Cerebral Venous Thrombolysis

VIROLOGY

Herpes Zoster and Multiple Sclerosis

29 (FEB)

VITAMIN

MRI in Vitamin B12 Deficiency Myelopathy 60 (FEB) 